AN ECOLOGICAL STUDY OF THE ART LIBRARY

\title{
Janice Johnson
}

This study investigated the ecology of students working in the Art Library. It focused on the activities of all students in the main room of the library between 3:00 p.m. and 3:30 p.m. During this time, the activities of everyone entering or present in the 1 ibrary were recorded. However, the behavior of three people, one man and two women, was recorded in more detail.

The main room of the art library is a square space with an entrance in the middle of the east wa71. A doorway to the second room on the lower level is directiy across from the entrance. To the left of the entrance is the reference and check-out desk. The librarian's desk is just beyond it. To the right of the doorway are open stacks and a stairway to the second floor. The card catalogue is basically in the center of the room. It is flanked by reference sections. The reference section on the right also contains new books. There are two tables in the room. One is located to the left of the card catalogue; the other behind the card catalogue. A double row of three study carrels is located behind the stairway, to the right of the card cata1ogue. In addition to the open stacks to the right of the doorway, there are stacks along the north wall and in the southwest corner of the room.

In the Art Library, there are four areas of high activity: the reserve desk, the card catalogue, the new book section, and the open stacks. Sixteen people asked for assistance at the reserve desk. Thirteen people used the open stacks. Eight people used the card catalogue. Seven people browsed through the new books. The stairway and entrance to the back room on the first floor were areas of medium activity, with five people going upstairs 


\section{Janice Johnson}

and into the back room. The areas of low activity were the two study tables and the study carrels. Three people studied at the tables, two at the table on the left and one at the table behind the card catalogue. Two people studied at the study carrels. Figure 1 indicates the activity zones which were observed.

Most of the activity in the library was transcient, solitary, and purposeful, especially in the high and medium activity zones. More of the social activity occured at the check-out or reserve desk. The relationship between the librarian and the students appeared impersonal, yet courteous. The students did not interact with each other for the most part. One student, however, dropped his hat and another picked it up. This may be considered an example of cooperation. There were more activities of a social type at the new book section al though they did not occur with great frequency. Two people walked in, looked at new books together, talked about the books, and then left. The card catalogue and stacks attracted high numbers of people but their activities in these areas were quite solitary. The people using the stacks and card catalogue were alone and did not engage in conversation.

The three people who were observed closely stayed in the library for extended periods of time. The first woman returned from the stacks to the table behind the card catalogue. There was a pile of books haphazardly arranged on the table. She added three books to the pile, sat down, and started flipping through them. She was surrounded by books as if she wanted to demarcate her own space. She, then, went to the card catalogue and to the stacks. In the meantime, the librarian began removing her books. When she 


\section{Janice Johnson}

returned she explained, rather tersely, that she was using the books. This minor conflict was resolved by compromise. The librarian said he was moving the books because he thought they would fall off the slanted table. He suggested that she put them on a chair. She agreed to pile the books on the chair and returned to the stacks. I thought that part of her irritation might have been caused by the destruction of her territory.

The man who was observed was studying at the carrels. He was reading his notes. He went to the stacks and brought a book back to his desk. While he was gone a woman came into the library, sat in the desk next to his, and stared into space, apparently waiting. He returned and they began talking. The man referred to something in his notebook. She took the notebook and read. He looked through the book he had just brought from the stacks. He went to the card catalogue, then to the reference section. While he was at the reference section, he engaged in a brief conversation with a woman at the study table next to it. He then returned to the study carrel and began reading. The interaction did not seem to be social. It appeared to be a form of cooperative study.

I had thought the Art Library was more of a social center than my observation indicated. In fact, I was a bit surprised. I considered the Art Library as a place to meet friends rather than a place to study. However, I observed more solitary activity than social activity, possibly due to the time of day and to the nearness of the semester end. Most of the people depended on the librarian to a great extent. However, it was an impersonal dependence. There seemed to be closer relationships between the people who were in the lowactivity zones than in the high-activity zones. The conversations were serious 


\section{Janice Johnson}

in these closer relationships. Most of the people using the library did not stay very long but seemed to want to get books as quickly as possible. Again, the time of day may have influenced this observation. Those who were there for longer periods created their own study spaces either by choosing a study carrel or by marking off territorial boundaries with books. I suspect that the activity zones would remain fairly constant throughout the day, but that the level of social interaction might fluctuate at different times of the day which may be a possibility for further study. 


\section{Janice Johnson}

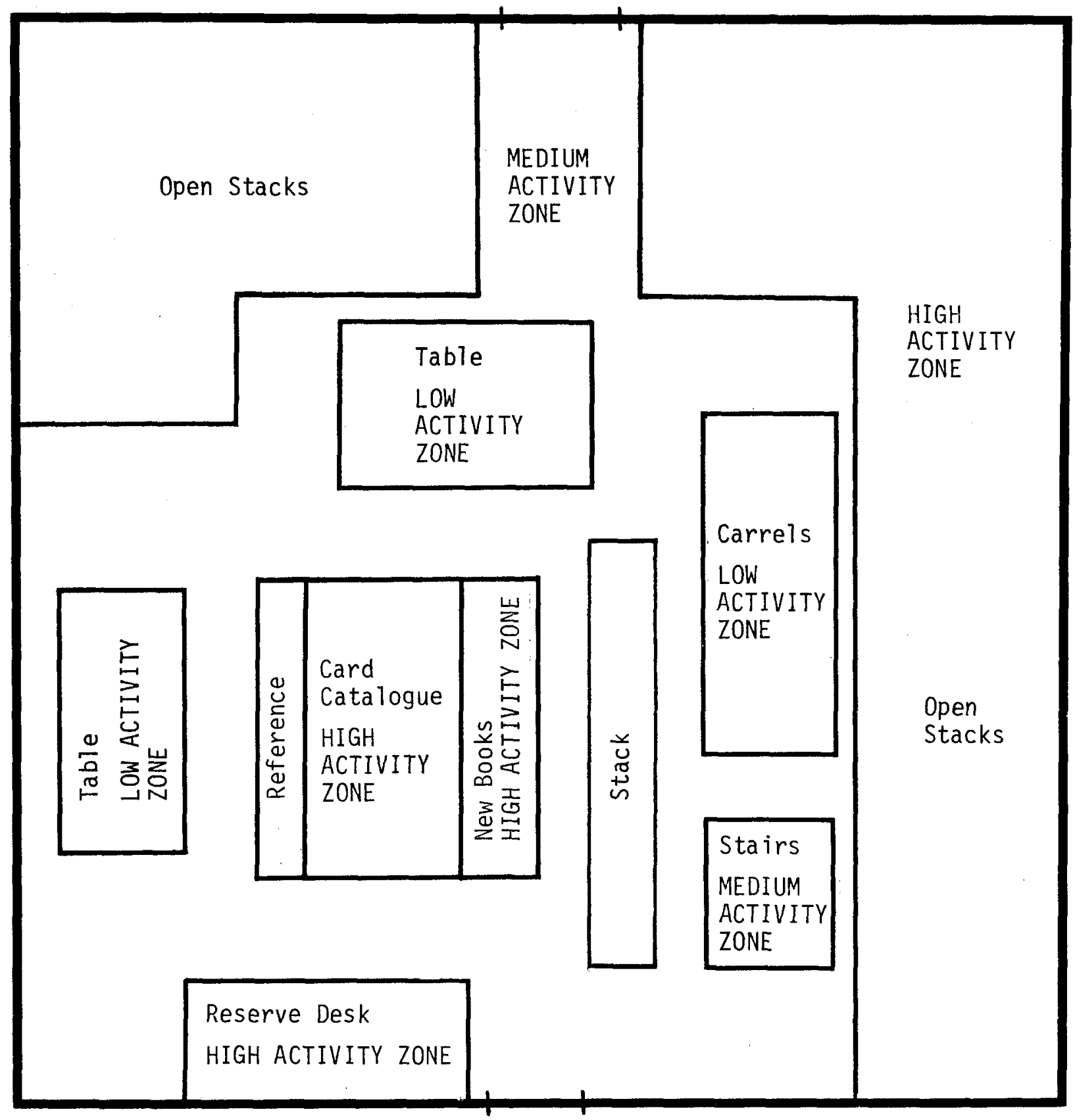

